\title{
Design of Internal Model Controller for an Open Loop Unstable CSTR Process
}

\author{
S. V. Prasanna Kumar ${ }^{1}$, Ritesh Singh $^{2}$, S. Nagammai ${ }^{3}$ \\ M.Tech, Electrical \& Electronics Engineering, Manipal University Jaipur, Jaipur, India ${ }^{1}$ \\ Assistant Professor, Electrical \& Electronics Engineering, Manipal University Jaipur, Jaipur, India ${ }^{2}$ \\ H.O.D, Electronics \& Instrumentation Engineering, K.L.N. College of Engineering, Madurai, India ${ }^{3}$
}

\begin{abstract}
A CSTR is an Continuously Stirred Tank Reactor with the main function of agitation and to achieve constant composition. It has an important role in chemical process plants. A CSTR has an higher degree of nonlinearity when compared with other chemical reactors, this is mainly due to the temperature variations that occur because of uncertainity in feed. Hence, temperature control is a strenuous task. The proposed work focusses on control of temperature in a jacketed chemical reactor, by effectively designing a internal model controller (IMC). The process is a open loop unstable system due to the effect of scale-up on the steady state and other dynamic characteristics. The proposed digital controller is capable of providing system stability, set point tracking and disturbance rejection. The simulation result shows the suitability of using the proposed controllers for control of the unstable CSTR process.
\end{abstract}

Keywords: IMC, CSTR, Digital Controller, Stability.

\section{INTRODUCTION}

The continuous flow stirred-tank reactor, also known as closed type agitator reactor, is a typical reactor type found in chemical process industries. A CSTR often refers to a model which is used to attain a specified output. As these chemical processes have to operate under a particular working order, they are subject to process hinderances. The classical two-state CSTR model is well-known to be capable of giving constructive behaviour. Bequette noted that, a three-state model (incorporating a jacket energy balance) could result in multiple steady-states under conditions whereas the two-state model exhibits a single steady state operating point.

Continuous stirred-tank reactors are open systems, where material is free to enter or exit the system, that operate on a unbalanced state, where the conditions in the reactor change with time. Reactants are continuously introduced into the reactor, while products are continuously removed. Usually, the modelling of an industrial CSTR is done by comparing with that of an ideally controlled reactor, which are driven under ambient conditions. Thus, under ideal reactor conditions, perfect mixing is considered so as to calculate the exact product inlet and outlet ratio. Hence, Temperature control of unstable CSTR process is generally crucial and complicated due to large system nonlinearity. Many researchers have developed controllers for SISO unstable CSTR process [4],[5].

There exist various techniques for designing a digital controller, both in transfer function approach and the state space approach. But the most prominent technique is to design internal model controller for modeled unstable process.

This paper is organized as follows: Mathematical modeling of the unstable CSTR process is given in section II, Digital controller design for the unstable CSTR process is given in section III, The simulated results are obtained and shown in section IV and finally, the Conclusions of the work are drawn in section $\mathrm{V}$

\section{PROCESS DESCRIPTION}

A continuous stirred tank reactor (CSTR), is considered where in a first order exothermic reaction $\mathrm{A} \rightarrow \mathrm{B}$ takes place at a temperature $T_{R}$ with a cooling jacket. The chemical reaction is first order with Arrhenius temperature dependence.

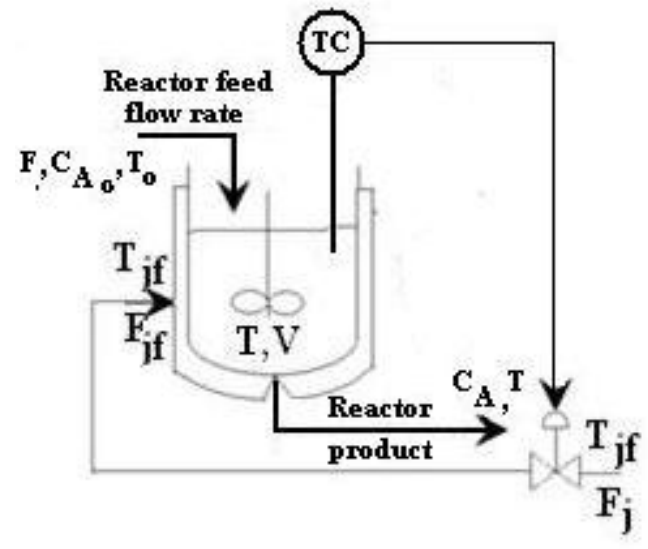

Fig. 1. CSTR process model.

In the jacketed CSTR the heat is either added or removed to compensate for the temperature difference between a cooling jacket fluid and the reactor fluid. The ODE's that model the CSTR behavior is given as equation [1.a]. The component material balance on the reactant gives:

$\frac{d C_{A}}{d t}=f_{1}\left(C_{A}, T_{R}, T_{j}\right)=\frac{q}{V}\left(C_{A 0}-C_{A}\right)-\mathrm{k}_{0} \mathrm{e}^{\frac{-\mathrm{E}_{\mathrm{a}}}{\mathrm{RT}_{\mathrm{R}}}} C_{A}$ 
Where ' $\mathrm{q}$ ' is the feed flow rate of the reactant, ' $\mathrm{C}_{\mathrm{A} 0}$ ' is the The disturbance matrix is, feed concentration, ' $\mathrm{C}_{\mathrm{A}}$ ' is the concentration of component in the reactor, ' $\mathrm{K}_{0}$ ' is the frequency factor, ' $\mathrm{E}_{\mathrm{a}}$ ' is the activation energy, ' $R$ ' is the ideal gas constant, ' $T_{R}$ 's the reactor temperature in degree Rankine. Where ' $(-\Delta H)$ ' is the rate of heat produced during reaction, ' $\mathrm{U}$ ' is is the heat transfer coefficient, ' $A$ ' is the heat transfer area, ' $T_{0}$ ' is the reactor feed temperature, ' $\mathrm{T}_{\mathrm{j}}$ ' is the jacket temperature in degree Rankine.

The energy balance in the jacket is,

$$
\frac{d T_{j}}{d t}=f_{3}\left(C_{A}, T_{R}, T_{j}\right)=\frac{q_{j f}}{V_{j}}\left(T_{j f}-T_{j}\right)+\left(\frac{\mathrm{UA}}{\mathrm{V}_{\mathrm{j}} \rho_{\mathrm{j}} C_{p j}}\right)\left(T_{R}-T_{j}\right)
$$

Where ' $\mathrm{q}_{\mathrm{j} f}$ ' is the jacket make up flow rate The variables ' $\mathrm{C}_{\mathrm{A} 0}$ ', ' $\mathrm{T}_{0}$ ', ' $\mathrm{q}$ ', ' $\mathrm{q}_{\mathrm{jf}}$ ', ' $\mathrm{T}_{\mathrm{j}}$ ' are all considered as inputs and out of which ' $\mathrm{C}_{\mathrm{A} 0}$ ' and ' $\mathrm{T}_{0}$ ' are considered as the disturbance variables. The manipulated variable is the reactor feed flowrate and the controlled variable is the the reactor temperature. The three nonlinear differential equations expressed in equations 1.a, and 1.b cannot be solved analytically. The approximate model is derived about the steady-state operating point of the reactor. The state space representation of the CSTR process in terms of deviation variables is given in equation [1.c].

$$
\left[\begin{array}{l}
\dot{C}_{A^{\prime}}{ }^{\prime} \\
\dot{T}_{R^{\prime}}{ }^{\prime} \\
\dot{T}_{j^{\prime}}{ }^{\prime}
\end{array}\right]=\left[\begin{array}{lll}
a_{11} & a_{12} & a_{13} \\
a_{21} & a_{22} & a_{23} \\
a_{31} & a_{32} & a_{33}
\end{array}\right]\left[\begin{array}{c}
C_{A^{\prime}}{ }^{\prime} \\
T_{R^{\prime}}{ }^{\prime}{ }^{\prime}
\end{array}\right]+\left[\begin{array}{ll}
b_{11} & b_{12} \\
b_{21} & b_{22} \\
b_{31} & b_{32}
\end{array}\right]\left[\begin{array}{c}
q^{\prime} \\
q_{i j}^{\prime}
\end{array}\right]+\left[\begin{array}{ll}
e_{11} & e_{12} \\
e_{21} & e_{22} \\
e_{31} & e_{32}
\end{array}\right]\left[\begin{array}{c}
C_{A 0^{\prime}} \\
T_{0}^{\prime}
\end{array}\right]
$$

The output state space model is,

$$
\left[\begin{array}{l}
y_{1} \\
y_{2} \\
y_{3}
\end{array}\right]=\left[\begin{array}{lll}
0 & 1 & 0
\end{array}\right]\left[\begin{array}{l}
C_{A}{ }^{\prime} \\
T_{R}{ }^{\prime} \\
T_{j}{ }^{\prime}
\end{array}\right]
$$

The output and input states are defined in the deviation variable form as,

$$
X=\left[\begin{array}{l}
x_{1} \\
x_{2} \\
x_{3}
\end{array}\right]=\left[\begin{array}{c}
C_{A}{ }^{\prime}-C_{A S} \\
T_{R}{ }^{\prime}-T_{R S} \\
T_{j}^{\prime}-T_{j}
\end{array}\right] u=\left[\begin{array}{c}
u_{1} \\
u_{2} \\
u_{3} \\
u_{4}
\end{array}\right]=\left[\begin{array}{c}
q^{\prime} \\
q_{j f}{ }^{\prime} \\
C_{A 0}{ }^{\prime} \\
T_{0}^{\prime}
\end{array}\right]
$$

The first two inputs are considered as the manipulated variables, while the last two inputs are disturbances.

The Jacobian matrix is,

Where, $k_{s}=\alpha \mathrm{e}^{-\left(\frac{E_{\mathrm{a}}}{R T_{\mathrm{Rs}}}\right)}$ and $k_{s}^{\prime}=k_{\mathrm{s}}\left(\frac{E_{\mathrm{a}}}{R T_{\mathrm{RS}}{ }^{2}}\right)$

$$
B=\left[\begin{array}{ll}
b_{11} & b_{12} \\
b_{21} & b_{22} \\
b_{31} & b_{32}
\end{array}\right]=\left[\begin{array}{ll}
\frac{\partial f_{1}}{\partial u_{1}} & \frac{\partial f_{1}}{\partial u_{2}} \\
\frac{\partial f_{2}}{\partial u_{1}} & \frac{\partial f_{2}}{\partial u_{2}} \\
\frac{\partial f_{3}}{\partial u_{1}} & \frac{\partial f_{3}}{\partial u_{2}}
\end{array}\right]=\left[\begin{array}{cc}
\frac{C_{A 0 s}-C_{A s}}{V} & 0 \\
\frac{T_{0 s}-T_{\mathrm{s}}}{V} & 0 \\
0 & \frac{T_{j f s}-T_{j s}}{V_{\mathrm{j}}}
\end{array}\right]
$$

$$
E=\left[\begin{array}{ll}
e_{11} & e_{12} \\
e_{21} & e_{22} \\
e_{31} & e_{32}
\end{array}\right]=\left[\begin{array}{ll}
\frac{\partial f_{1}}{\partial u_{3}} & \frac{\partial f_{1}}{\partial u_{4}} \\
\frac{\partial f_{2}}{\partial u_{3}} & \frac{\partial f_{2}}{\partial u_{4}} \\
\frac{\partial f_{3}}{\partial u_{3}} & \frac{\partial f_{3}}{\partial u_{4}}
\end{array}\right]=\left[\begin{array}{cc}
\frac{q_{s}}{V} & 0 \\
0 & \frac{q_{s}}{V} \\
0 & 0
\end{array}\right]
$$

Substituting the numerical values given in Table I, the above constants are evaluated and the state space model of the system thus obtained is given as, The transfer function which relates the Reactor temperature $\left(T_{R}\right)$ to the cooling water flow rate $\left(q_{i f}\right)$ of the plant is expressed as,

$\frac{\mathrm{T}_{\mathrm{R}}(\mathrm{s})}{\mathrm{q}_{\mathrm{jf}}(\mathrm{s})}=\frac{-4.753 \mathrm{~S}-38}{\mathrm{~s}^{3}+9.34 \mathrm{~S}^{2}+16.98 \mathrm{~S}-34.2}$

The transfer function indicates that the open loop system is unstable (presence of unstable pole) due to the inclusion of cooling jacket dynamics.

Table. I. Reactor steady state parameter values:

\begin{tabular}{|c|l|c|}
\hline Variable & \multicolumn{1}{|c|}{ Description } & Value \\
\hline $\mathrm{C}_{\mathrm{Aos}}$ & $\begin{array}{l}\text { Steady state Feed concentration } \\
\left(\mathrm{lb} \mathrm{mol} / \mathrm{ft}^{3}\right)\end{array}$ & 0.132 \\
\hline$T_{0 s}$ & $\begin{array}{l}\text { Steady state Feed temperature } \\
\left({ }^{\circ} \mathrm{F}\right)\end{array}$ & 60 \\
\hline$T_{R S}$ & $\begin{array}{l}\text { Steady state Reactor } \\
\text { temperature }\left({ }^{\circ} \mathrm{F}\right)\end{array}$ & 101.1 \\
\hline$T_{j f s}$ & $\begin{array}{l}\text { Steady state cooling water } \\
\text { input temperature }\left({ }^{\circ} \mathrm{F}\right)\end{array}$ & 0 \\
\hline$T_{j s}$ & $\begin{array}{l}\text { Steady state jacket temperature } \\
\left({ }^{\circ} \mathrm{F}\right)\end{array}$ & 80 \\
\hline $\mathrm{C}_{\mathrm{As}}$ & $\begin{array}{l}\text { Steady state Reactor } \\
\text { concentration }\left(\mathrm{lb} \text { mol } / \mathrm{ft}^{3}\right)\end{array}$ & 0.066 \\
\hline$q_{s}$ & $\begin{array}{l}\text { Steady state Feed flow rate } \\
\left(\mathrm{ft}^{3} / \mathrm{hr}\right)\end{array}$ & 340 \\
\hline$q_{j f s}$ & $\begin{array}{l}\text { Steady state cooling water } \\
\text { flow rate }\left(\mathrm{ft}^{3} / \mathrm{hr}\right)\end{array}$ & 24 \\
\hline
\end{tabular}

\section{CONCEPTS OF IMC FOR UNSTABLE} PLANTS

In the chemical engineering field, the internal model controller is a popular technique and it is named so because the controller has an explicit model of the plant as its part. The IMC feedback configuration is shown in Fig.2.

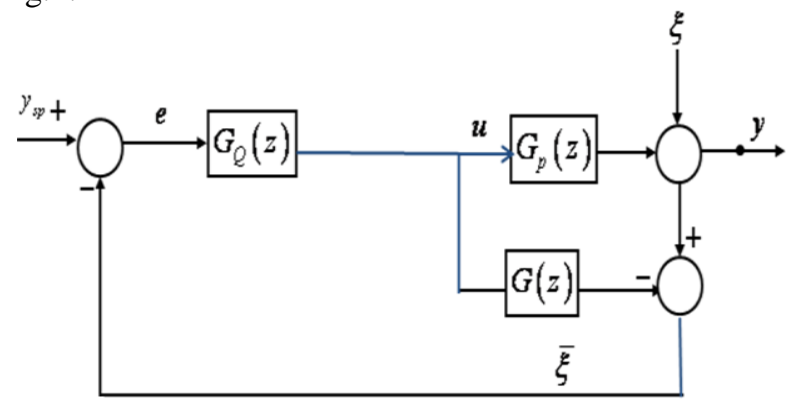

Fig.2. IMC feedback configuration. 
The actual transfer function of the plant is denoted as $G_{p}\left(z^{-1}\right)$ and its model by $G\left(z^{-1}\right)$. Let the model transfer function be factored as

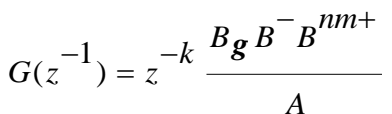

Where,

$B_{g}$ is the factor of $\mathrm{B}$ with the roots inside the unit circle and with positive real parts. $B^{-}$is the factor of $\mathrm{B}$ that have roots with negative real part and which may lie either inside, outside or on the unit circle. $B^{n m+}$ refers to that part of $\mathrm{B}$ containing non minimum zeros of $\mathrm{B}$ with positive real parts. The equivalence of standard control configuration with IMC is shown in Fig.3.

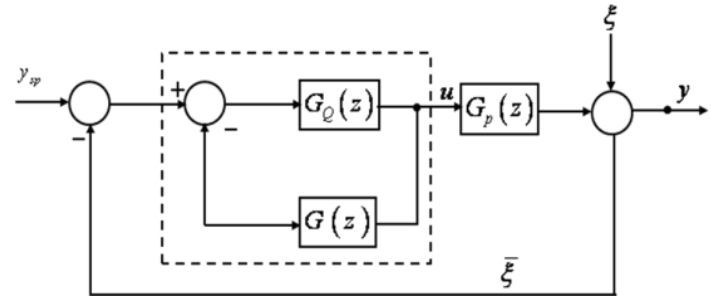

Fig.3. Equivalence of standard control configuration with IMC

In this schematic diagram, the block shown in dotted line is $G_{C}$ (controller in the conventional form) and is expressed as,

$$
G_{C}=\frac{G_{Q}(Z)}{1-G(Z) G_{Q}(Z)}
$$

Suppose the plant $G\left(z^{-1}\right)$ is containing one unstable pole. The internal stability of the system is assured if the following conditions are satisfied.

a) $G_{Q}(Z)$ is stable.

b) At the unstable poles $\mathrm{p}_{\mathrm{i}}$ of the plant $G\left(z^{-1}\right)$, $\left(1-G(Z) G_{Q}(Z)\right)$ is zero.

That is, $\left.\left(1-G(Z) G_{Q}(Z)\right)\right|_{p_{i}}=0$

It is achieved by introducing a parameter $\beta$ in the definition of $G_{Q}(Z)$.

$G_{Q}(Z)=G^{\dagger} G_{f}\left(1+\beta z^{-1}\right)$

Where,

$G^{\dagger}=\frac{A}{B_{g} B_{S}{ }^{-} B_{r}{ }^{n m+}}$

$B_{s}^{-}$is the steady state equivalent of factor of $B^{-}, B_{r}^{n m+}$ is $B^{n m+}$ with reversed coefficients,

Substituting the definition of $G_{Q}(Z)$ given in Equation (2.e) into Equation (2.f), we get
$\left.\left(1-\mathrm{G} G^{\dagger} G_{f}\left(1+\beta z^{-1}\right)\right)\right|_{z=p_{i}}=0$

Solving this, we obtain

$\beta=p\left(\left.\frac{1}{\mathrm{G} G^{\dagger} G_{f}}\right|_{z=p_{i}}-1\right)$

The noise and model-mismatch have mainly high frequency components. To account for this, a low pass filter of the form is used.

$G_{f} \square \frac{B_{f}}{A_{f}}=\frac{(1-\alpha)}{1-\alpha z^{-1}}$,

where $1>\alpha>0$

The IMC equivalent conventional feedback controller is given by

$G_{C}=\frac{B_{f}{ }^{A}}{B_{g}\left(A_{f} B_{s}{ }^{-} B_{r}{ }^{n m+}-B_{f} B^{-} B_{r}{ }^{n m+} z^{-k}\left(1+\beta z^{-1}\right)\right)}=\frac{S(z)}{R(z)}$

Digital internal model controller design:

The discrete version of the continuous time transfer function is obtained and is given by $\mathrm{G}(\mathrm{z})$.

$$
\begin{gathered}
\frac{T(s)}{F_{j f}(s)}=\frac{-4.753 s-38}{s^{3}+9.34 s^{2}+16.98 s-34.2} \\
G(z)=z^{-1} \frac{\left(-0.237 \times 10^{-3}-1.71 \times 10^{-5} z^{-1}+0.218 \times 10^{-3} z^{-2}\right)}{1-2.91 z^{-1}+2.82 z^{-2}-0.911 z^{-3}} \\
\quad=z^{-1} \frac{-0.237 \times 10^{-3}\left[1+0.96 z^{-1}\right]\left[1-0.95 z^{-1}\right]}{1-2.91 z^{-1}+2.82 z^{-2}-0.911 z^{-3}}=z^{-k} \frac{B(z)}{A(z)}
\end{gathered}
$$

Comparing with an equation (6), we find that

$\mathrm{A}=1-2.91 \mathrm{z}^{-1}+2.82 \mathrm{z}^{-2}-0.911 \mathrm{z}^{-3}$

$B_{g}=-0.237 \times 10^{-3}\left[1-0.95 z^{-1}\right]$

$\mathrm{B}^{-}=\left[1+0.96 \mathrm{z}^{-1}\right]$

$B^{n m+}=1$

$k_{p}=-0.237 \times 10^{-3}$

The $\mathrm{Q}$ form of IMC is obtained using the formula,

$G_{Q}(Z)=\frac{A}{B_{g} B_{s}{ }^{-} B_{r}{ }^{n m+}} \frac{1-\alpha}{1-\alpha z^{-1}}\left(1+\beta z^{-1}\right)$

It is evaluated that,

$B_{r}^{n m+}=1$

$B_{S}{ }^{-}=1.96$

$B_{\boldsymbol{g}}=-0.237 \times 10^{-3}\left[1-0.95 z^{-1}\right]$

The filter factor $\alpha$ is chosen as $\alpha=0.1$ and $\beta$ is evaluated

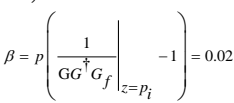


The IMC equivalent conventional feedback controller is given by,

$$
\begin{aligned}
& { }_{C} C=\frac{B_{f}{ }^{A}}{B_{g}\left(A_{f} B_{s}{ }^{-} B_{r}{ }^{n m+}-B_{f} B^{-} B_{r}{ }^{n m+} z^{-k}\left(1+\beta z^{-1}\right)\right)}=\frac{S(z)}{R(z)} \\
& S(z)=0.9-2.6 z^{-1}+2.5 z^{-2}-0.77 z^{-3}-0.016 z^{-4} \\
& R(z)=10^{-3}\left(0.54+0.26 z^{-1}+0.28 z^{-2}\right)
\end{aligned}
$$

\section{SIMULATION RESULTS:}

In order to analyze the performance of the proposed controllers, namely the figures shown in Fig.5 and Fig.6 are simulated using MATLAB. The controller term $\frac{S(z)}{R(z)}$ is evaluated for simulation. The time response of CSTR process in open loop mode is shown in Fig.4.

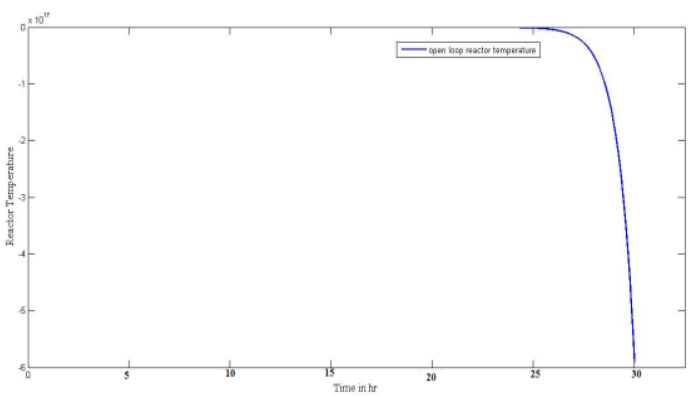

Fig.4. Open loop step response of the unstable CSTR process

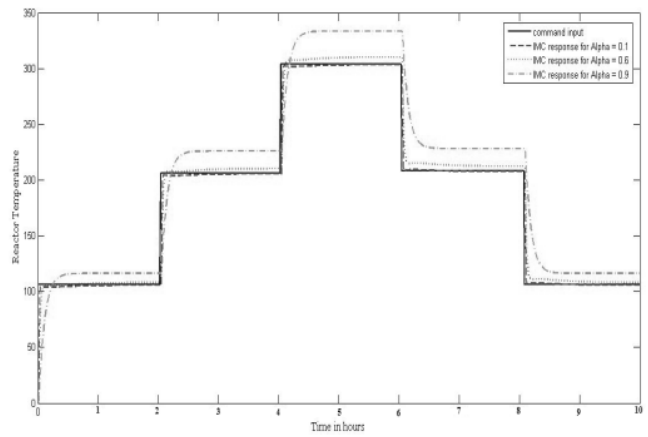

Fig.5. IMC servo response to set point change in coolant flow rate

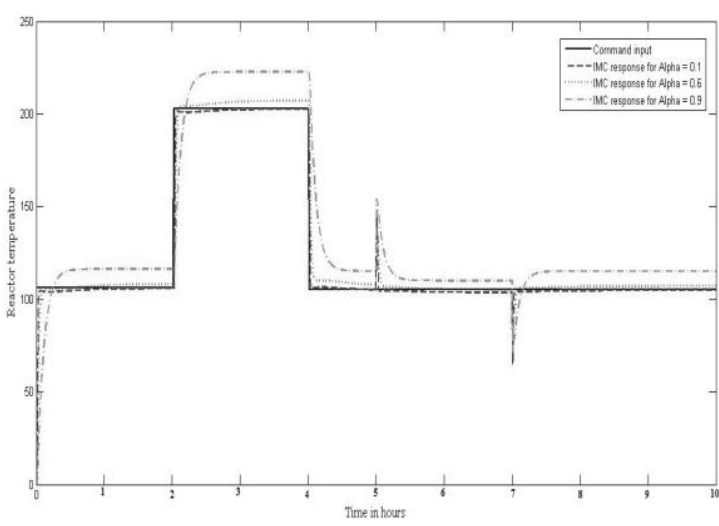

Fig.6. IMC Servo - Regulatory response to step disturbance of magnitude 10 begins at 5 hours and ends at 7 hours.

\section{CONCLUSION}

Hence Internal Model controller algorithms are demonstrated for a modeled unstable jacketed CSTR process. The time response shows that, the settling time, overshoot and rise time constraints are almost met. Hence, Internal Model Controller reduces uncertainity of the system and improves stability.

\section{REFERENCES}

[1]. Singh. A, Patil. M.D, "Design of digital controller using pole placement method" International Conference on "Control, Automation, Communication and Energy Conservation", 2009, IEEE Xplore

[2]. A course on Digital Control, Kannan M. Moudgalya, IIT Bombay

[3]. Bequette,B.W., Process control: modeling, design, and simulation ,Prentice Hall, New York(1998)

[4]. M.Chidambaram \& Ch.Yugender , "Model Reference Cascade Control of Nonlinear Systems: Application to an Unstable CSTR" Chemical Engineering Communications , Volume 113, Issue 1, March 1992, pages 15-29

[5]. Ayadeva Bhat, M.Chidambaram \& K.P.Madhavan, "Nonlinear Feedback Control of a CSTR", Chemical Engineering Communications, Volume 101, Issue 1, 1991

[6]. Rivera .D.E., M. Morari, and S. Skogestad, (1986) "Internal Model Control. 4. PID Controller Design", Ind. Eng. Chem. Process Des. Dev. 25,252

[7]. Morari .M and E. Zafiriou. (1989) Robust Process Control, Prenctice-Hall. 